\title{
The Forecast of the Methane Concentration Changes for the Different Time Periods on the Arctic Island Bely
}

\author{
Alexander Medvedev ${ }^{1,2, a)}$, Alexander Sergeev ${ }^{1,2, b)}$, Andrey Shichkin ${ }^{1,2, c)}$, Elena \\ Baglaeva $^{1,2, \text { d) }}$, Irina Subbotina ${ }^{2, e)}$, Alexander Buevich ${ }^{1,2, f)}$, and Marina Sergeeva ${ }^{2, g}$ ) \\ ${ }^{I}$ Ural Federal University, Mira str., 19, Ekaterinburg, RUSSIA 620002 \\ ${ }^{2}$ Institute of Industrial Ecology UB RAS, S. Kovalevskoy str., 20, Ekaterinburg, RUSSIA 620990 \\ ${ }^{a)}$ Corresponding author: alnikmed52@gmail.com \\ b)aleksandrpsergeev@gmail.com \\ c)and@ecko.uran.ru \\ d)elenbaglaeva@gmail.com \\ e)iesub@mail.ru \\ f)bagalex3@gmail.com \\ g)marin@ecko.uran.ru
}

\begin{abstract}
The paper predicts the changes in the concentration of one of the main greenhouse gases - methane $\left(\mathrm{CH}_{4}\right)$. The forecast was made for three different time periods, each of which had its own characteristics of the dynamics of changes in the concentration of $\mathrm{CH}_{4}$. Data for the study were collected while monitoring the content of the main greenhouse gases in the surface layer of atmospheric air in the Russian Arctic (Bely Island, Yamalo-Nenets Autonomous Okrug). We compared the results of the models prediction based on the two types of artificial neural networks: Elman and nonlinear autoregressive neural network with external input (NARX). NARX showed a high prediction accuracy for all studied time intervals.
\end{abstract}

\section{INTRODUCTION}

The Arctic is one of the four most vulnerable regions of the world to climate change. The ongoing effects of these changes on the Arctic environment are great and, unlike many other regions of the planet, including the other most vulnerable to climate change, can have a significant reverse impact on the global climate, which determines the global significance of climate change in the Arctic [1]-[3].

Today, many questions concerning the mechanisms responsible for the rapid melting of Arctic ice and degradation of permafrost, and the contribution of natural and anthropogenic factors to the observed processes remain unresolved. Researchers attribute the expected changes in the state of permafrost to the danger of a sharp increase in the flow of naturally occurring greenhouse gases contained in permafrost to the atmosphere, which should contribute to the greenhouse effect. Estimates of the positive feedback between global warming and the indicated greenhouse gas emissions vary from small to significant. Uncertainty is exacerbated by a lack of understanding of the role of Arctic ecosystems in the global carbon cycle. The cycles of the main long-lived greenhouse gases directly (carbon dioxide $\left(\mathrm{CO}_{2}\right)$, methane $\left(\mathrm{CH}_{4}\right)$, chlorofluorocarbons) participate in the global carbon cycle. Such greenhouse gases persist in the atmosphere for decades and changes in their content in the atmosphere have a long-term impact on the climate. At present, the evolution and climate-forming role of methane has been studied in most detail [1]-[3].

For predicting such complex dynamic systems, models based on artificial neural networks (ANN) [4]-[20], in particular networks such as Elman and NARX [4]-[20], are well suited. Elman's neural network is a network that consists of 2 layers, in which the entire hidden layer is covered by dynamic feedback. The NARX network is a 
recurrent dynamic multi-level feedback network. The standard NARX network is a two-layer back distribution network.

\section{MATERIALS AND METHODS}

Measurements of greenhouse gases methane, carbon monoxide, carbon dioxide, and water vapor were made on the Arctic Island, Bely, YNAO, Russia. The island is located $9 \mathrm{~km}$ north of the Yamal Peninsula in the Kara Sea (Fig.1).

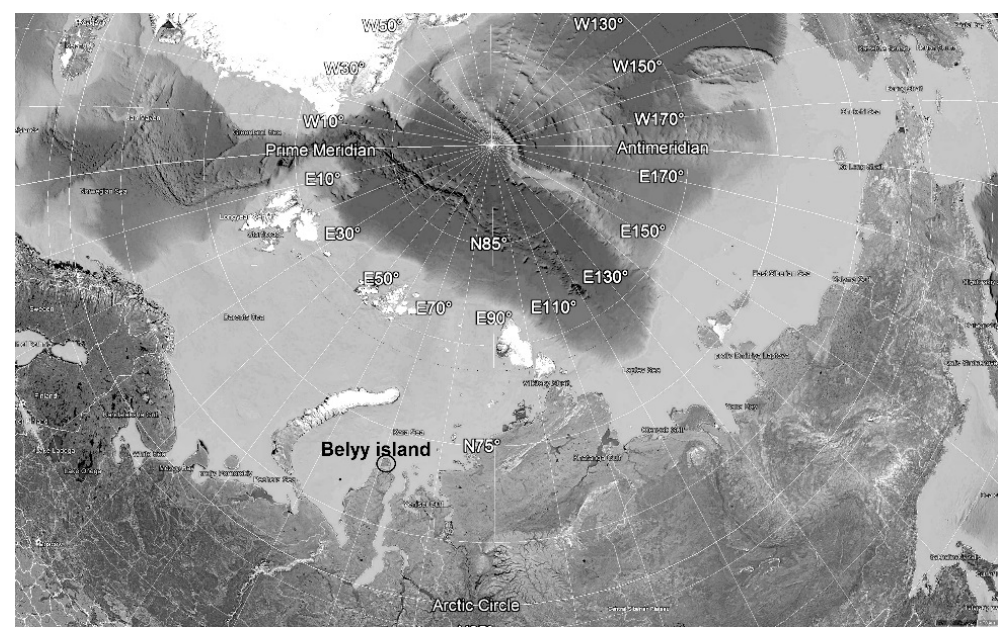

FIGURE 1. Place of the measurements (Google Earth).

Concentrations of greenhouse gases were measured by a cavity ring-down spectrometer Picarro G2401. The main meteorological parameters (temperature, humidity, atmospheric pressure, wind speed and direction) were also measured. The measurements were carried out by the Vaisala AWS310 weather station. Data of the gas concentrations and meteorological parameters were synchronized.

To predict the concentration of methane in the surface layer of atmospheric air, three-time intervals with a duration 168 hours each were chosen. Each selected interval had its own peculiarities of changes in methane concentration. The interval I was characterized by a pronounced diurnal change. During the day the concentration grew, at night it fell. During the interval II, the concentration smoothly changed, reaching a minimum in the middle. The interval III also had a pronounced course of methane concentration, but the changes occurred several times a day. Each interval was divided into two subsets: a first 144 hours was used to train the network, and the last 24 hours was used only for prediction. Weather data were fed to the ANN input, which was synchronized in time with $\mathrm{CH} 4$ content measurements.

The ANNs structure was determined by the computer simulation. The time interval and meteorological parameters were fed to the input, the hidden layer consisted of several neurons, and the output layer represented the $\mathrm{CH} 4$ concentration corresponding to the time interval. For the learning procedure, the Levenberg-Marquardt training algorithm was used. The number of neurons in the hidden layer in Elman and NARX was selected using the minimum mean square error (RMSE). The number of neurons ranged from 5 to 25. Each network was trained 500 times. Then the best of them was selected.

Indices mean absolute error (MAE) (1), RMSE (2), and the index of agreement (d), (a standardized measure of the degree of model prediction error and varies between 0 and 1 , where a value of 1 indicates a perfect match, and 0 indicates no agreement at all [21] (3) was verified the predictive accuracy of each selected approach between the prediction and raw data from the training data set.

$$
\begin{gathered}
M A E=\frac{\sum_{i=1}^{n}\left|z_{\text {mod }}\left(x_{i}\right)-z\left(x_{i}\right)\right|}{n}, \\
R M S E=\sqrt{\frac{\sum_{i=1}^{n}\left(z_{\text {mod }}\left(x_{i}\right)-z\left(x_{i}\right)\right)^{2}}{n}}, \\
d=1-\frac{\sum\left|z_{\text {mod }}\left(x_{i}\right)-z\left(x_{i}\right)\right|}{\sum\left(\left|z_{\text {mod }}\left(x_{i}\right)-\bar{Z}\right|+\left|z\left(x_{i}\right)-\bar{Z}\right|\right)}
\end{gathered}
$$

where $z_{m o d}\left(\boldsymbol{x}_{i}\right)$ is a predicted concentration in location $\boldsymbol{x}_{i}, z\left(\boldsymbol{x}_{i}\right)$ is a measured concentration, $\bar{Z}$ is a mean concentration, and $n$ is a number of points. 


\section{RESULTS AND DISCUSSION}

The final neuron number in the hidden layer was 20 for NARX network. Table 1 shows the parameters used to compare the performance of the different methods (the best values demonstrated by NARX for the test interval are in bold).

TABLE 1. Accuracy assessment indices of the $\mathrm{CH}_{4}$ concentration.

\begin{tabular}{ccccccc} 
Index & \multicolumn{2}{c}{ MAE } & \multicolumn{2}{c}{ RMSE } & \multicolumn{2}{c}{$\mathrm{d}$} \\
\hline Network & NARX & Elman & NARX & Elman & NARX & Elman \\
\hline I period & $\mathbf{0 . 0 3}$ & 0.03 & $\mathbf{0 . 0 3}$ & 0.04 & $\mathbf{0 . 6 2}$ & 0.46 \\
\hline II period & $\mathbf{0 . 0 1}$ & 0.02 & $\mathbf{0 . 0 1}$ & 0.02 & $\mathbf{0 . 5 3}$ & 0.41 \\
\hline III period & $\mathbf{0 . 0 0 5}$ & 0.007 & $\mathbf{0 . 0 0 5}$ & 0.01 & $\mathbf{0 . 6 3}$ & 0.56
\end{tabular}

Taking into account all indices, the NARX network showed better forecast accuracy. Figure 2 demonstrates the results of predictions of changes in $\mathrm{CH}_{4}$ concentration.
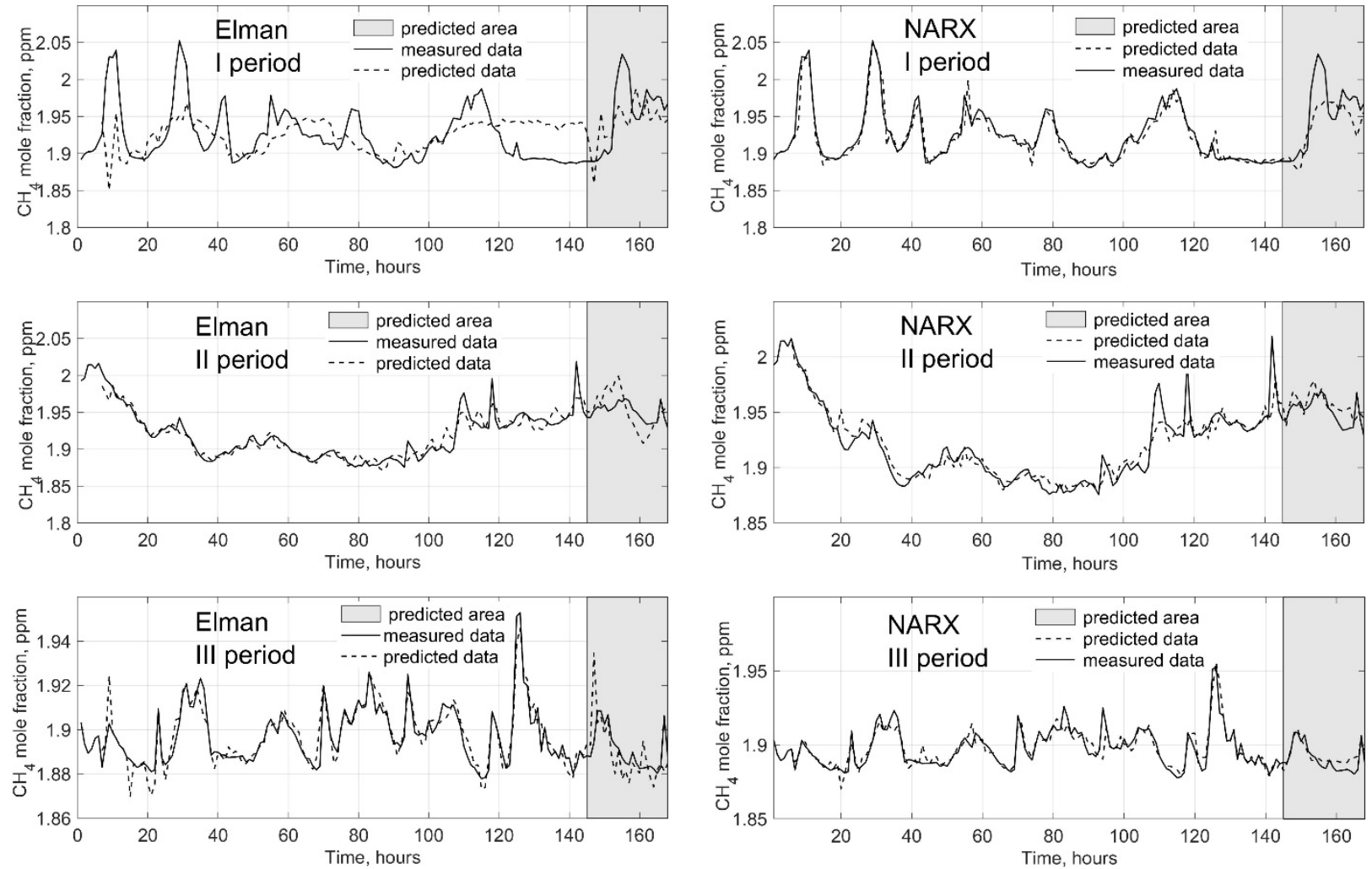

FIGURE 2. ANN predictions for different time periods.

\section{CONCLUSION}

The forecast of the changes in the $\mathrm{CH}_{4}$ concentration in the surface layer of the atmospheric air for the different time intervals was made. For each interval the changes in the concentration of methane had its own characteristics. The prediction was made by an artificial neural networks Elman and NARX.

For all investigated time intervals, the neural networks gave accurate results. The most accurate was NARX network. The authors believe that this approach can be successfully used in the problems of predicting the dynamics of changes in the concentrations of greenhouse gases. 


\section{REFERENCES}

[1] A.V. Zagorsky, The Arctic: a zone of peace and cooperation, edited by A.V. Zagorsky (IMEMO RAN Moscow, 2011), pp.195, in Russian.

[2] C Nullis, Provisional WMO Statement on the Status of the Global Climate in 2016. World Meteorological Organization (2016).

[3] M.C. Serreze and R. G. Barry, "Processes and impacts of Arctic amplification: A research synthesis", Global and Planetary Change 77, 85-96 (2011).

[4] M. Ardalani-Farsa and S. Zolfaghari, "Chaotic time series prediction with residual analysis method using hybrid Elman-NARX neural networks", Neurocomputing 73, 2540-2553 (2010).

[5] A.V. Dmitriev, "Time series prediction of morbidity using artificial neural networks", Biomedical Engineering 47, 1, 43-45 (2013).

[6] J.M. Jr. Menezes and G.A. Barreto, "Long-term time series prediction with the NARX network: An empirical evaluation", Neurocomputing 71, 3335-3343 (2008)

[7] E. Pisoni, M. Farina, C. Carnevale and L. Piroddi, "Forecasting peak air pollution levels using NARX models", Engineering Applications of Artificial Intelligence 22, 593-602 (2009).

[8] G. Zhang, "Time series forecasting using a hybrid ARIMA and neural network model", Neurocomputing 5, 159-175 (2003).

[9] G. Dimitrov, G. Panayotova, I. Garvanov, O. Bychkov, P. Petrov and A. Angelov, "Performance analysis of the method for social search of information in university information systems", in 3rd International Conference on Artificial Intelligence and Pattern Recognition (AIPR), (Lodz, Poland, IEEE, 2016), pp. 149-153.

[10] A. Erdil and E. Arcaklioglu, "The prediction of meteorological variables using artificial neural network", Neural Computing \& Application 22, 1677-1683 (2013).

[11] K. Mohanty and T. J. Majumdar, "Using artificial neural networks for synthetic surface fitting and the classification of remotely sensed data", International Journal of Applied Earth Observation and Geoinformation 1(1), 78-84 (1999)

[12] G. Panayotova, G. Dimitrov, P. Petrov and O. Bychkov, "Modeling and data processing of information systems", in 3rd International Conference on Artificial Intelligence and Pattern Recognition (AIPR), (Lodz, Poland, IEEE, 2016), pp. 154-158.

[13] Z. Polkowski, J. Vasilev, D. Zajac and A. L. Florina, "A content analysis of existing educational portals for teaching data warehouse and business intelligence", Proceedings of the 8th International Conference on Electronics, Computers and Artificial Intelligence, ECAI 2016 7861146, 2017, pp. 420-437.

[14] A. Russo, F. Raischel and P. Lind, "Air quality prediction using optimal neural networks with stochastic variables", Atmos. Environ. 79, 822-830 (2013).

[15] A.P. Sergeev, A.G. Buevich, E.M. Baglaeva and A.V. Shichkin, "Combining spatial autocorrelation with machine learning increases prediction accuracy of soil heavy metals", Catena 174, 425-435 (2019).

[16] S. Stojadinovic, "Prediction of fly rock launch velocity using artificial neural networks", Neural Computing \& Application 27, 515-524 (2016).

[17] D.A. Tarasov, A.G. Buevich, A.P. Sergeev and A.V. Shichkin, "High Variation Topsoil Pollution Forecasting in the Russian Subarctic: Using Artificial Neural Networks Combined with Residual Kriging", Applied Geochemistry 88(B), 188-197, (2018).

[18] J. Vasilev, V.F. Turygina, A.I. Kosarev and Y.Y. Nazarova, "Mathematical optimization in environmental economics. Algorithm of gradient projection method", in International Multidisciplinary Scientific GeoConference Surveying Geology and Mining Ecology Management, SGEM, 2016, pp. 349-356.

[19] Q. Zhou, H. Jiang, J. Wang and J. Zhou, "A hybrid model for PM2.5 forecasting based on ensemble empirical mode decomposition and a general regression neural network", Sci. Total Environ. 496, 264-274 (2014).

[20] Sergeev A.P., Buevich A.G., Medvedev A.N., Spasov K.B., Kosachenko A.I., Moskaleva A.S. "On the Hybrid Models of Soil Contaminants Concentrations Predicting in Subarctic Region", AIP Conference Proceedings 1978, 440006 (2018); https://doi.org/10.1063/1.5044035.

[21] Alexander G. Buevich, Alexander N. Medvedev, Alexander P. Sergeev, Dmitry A. Tarasov, Andrey V. Shichkin, Marina V. Sergeeva, and T. B. Atanasova, "Modeling of Surface Dust Concentrations Using Neural Networks and Kriging", AIP Conference Proceedings, 1789, 020004 (2016).

[22] Willmott, C.J., 1981. "On the Validation of Models", Physical Geography 2, 184-194. 